\title{
A Combined Study of Macroseismic Data and Focal Mechanisms Applied to the West-Bohemian Earthquake, Czechoslovakia
}

\author{
J. Zahradník, ${ }^{1}$ M. Antonini, ${ }^{5}$ G. Grünthal ${ }^{3}$, J. JanskÝ,${ }^{1}$ D. ProcháZková, ${ }^{2}$ \\ E. SCHMEDES, ${ }^{4}$ A. ŠPIČÁK ${ }^{2}$ and J. ZEDNíK ${ }^{2}$
}

Abstract - The main shock of the West-Bohemian earthquake swarm, Czechoslovakia, (magnitude $m=4.5$, depth $h=10 \mathrm{~km}$ ) exhibits an irregular areal distribution of macroseismic intensities $6^{\circ}$ to $7^{\circ}$ MSK-64. Four lobes of the $6^{\circ}$ isoseismal are found and the maximum observed intensity is located at a distance of $8 \mathrm{~km}$ from the instrumentally determined epicentre. This distribution can be explained by the energy flux of the direct $S$ wave generated by a circular source, the hypocentral location and focal mechanism of which are taken from independent instrumental studies. The theoretical intensity, which is assumed to be logarithmically proportional to the integrated squared ground-motion velocity (i.e., $I=$ const $\left.+\log \int v^{2}(t) d t\right)$, fits the observed intensity with an overall root-mean-square error less than $0.5^{\circ}$. It is important that the present intensity data can also be equally well explained by the isotropic source. The fit was attained by means of a horizontally layered model though large fault zones and an extended sedimentary basin suggest a significant lateral heterogeneity of the epicentral region. The results encourage a broader application of the simple modelling technique used.

Key words: Macroseismic data, synthetic isoseismals, focal mechanism, earthquake swarm, circularsource model, local geological conditions.

\section{Introduction}

The present paper deals with the main shock of the 1985/86 West-Bohemian earthquake swarm. Most of the activity lasted from December 1985 to February 1986. Hundreds of shocks were macroseismically felt and instrumentally recorded during that period. The main shock occurred on December 21, 1985, the focal depth being $10 \mathrm{~km}$ and the magnitude 4.5 . This shock as well as the whole swarm were briefly described by Procházková (1988) and details can be found in PROCHÁZKOVÁ, ed. (1987).

${ }^{1}$ Institute of Geophysics, Charles University, V Holešovičkách 2, 18000 Praha 8, Czechoslovakia.

${ }^{2}$ Geophysical Institute, Czechosl. Academy of Sciences, Bočni II, 14131 Praha 4, Czechoslovakia.

${ }^{3}$ Central Institute for Physics of the Earth, Acad. Sci. GDR, Telegrafenberg, Potsdam, GDR-1561.

${ }^{4}$ Geophysical Observatory of University of Munich, Ludwigshöhe 8, D-8080 Munich, FRG.

${ }^{5}$ Institute of Pure and Applied Geophysics, University of Munich, Theresienstr. 41, D-8000 Munich, FRG. 
The macroseismic field of the main shock was asymmetrical, intensities $I \geq 6^{\circ}$ MSK -64 being encircled by a four-lobe isoseismal. Moreover, the largest intensity $\left(7^{\circ}\right)$ occurred at a distance of $8 \mathrm{~km}$ from the instrumental epicentre. Elongated isoseismals and locally increased intensities are often reported in the literature and qualitatively interpreted as caused by faults, sedimentary structures and local geological conditions. Thus, the first objective of the present paper was to interpret in such a way the intensities $I \geq 6^{\circ}$ for the studied event. It will be shown that there is no simple geometrical relation between the isoseismal lobes and main structural elements of the epicentral region.

The most convenient next step to take would be to formulate a quantitative 3-D structural model and the source model, to compute synthetic isoseismals and to compare them with observations. Unfortunately, there are not enough quantitative structural data for such an undertaking. Instead, the second objective of the paper is to use a highly simplified crustal model without lateral heterogeneities and to concentrate on the source and the intensity modelling. The circular double-couple source is used, with parameters taken from instrumental observations. The intensity is assumed to be logarithmically proportional to the energy flux of direct $S$ waves computed by the ray method. Comparisons between the theoretical and observed intensities are used to investigate the importance of focal parameters in formation of the macroseismic field.

For analogous studies see, for example, PANZA and Cuscito (1982) and SuHADOLC et al. (1988), where synthetic seismograms corresponding to a point source were computed and their maximum amplitudes were related to the intensity. The mode-summation method, used by these authors, is advantageous for treating interference waves. A finite-dimension source, necessary if larger earthquakes are considered, was used by BoATWRIGHT (1986).

\section{Data}

Seismic activity and geology. The region of West Bohemia is well-known for the swarm-type earthquake activity. The 1985/86 swarm belongs to the largest earthquake observed there since the 12th century. The last swarms of a comparable size in terms of duration and energy release occurred in 1903 and 1908. Minor swarms are more frequent and were observed, e.g., in 1929, 1936/37, 1962 and 1973.

The swarm activity reflects the complex tectonic setting of West Bohemia. Two large fault systems intersect in the region. One of them is orientated roughly NW-SE, the other being nearly perpendicular to the former. Four main faults of these two systems are depicted in Figure 1. The Mariánské Lázně fault (M.L.), denoted by No. 1 in Figure 1, will be discussed in greater detail later in this section. Although the largest faults date back to the Proterozoic era, they were reactivated several times and their activity persists. The age, size and geologically documented 


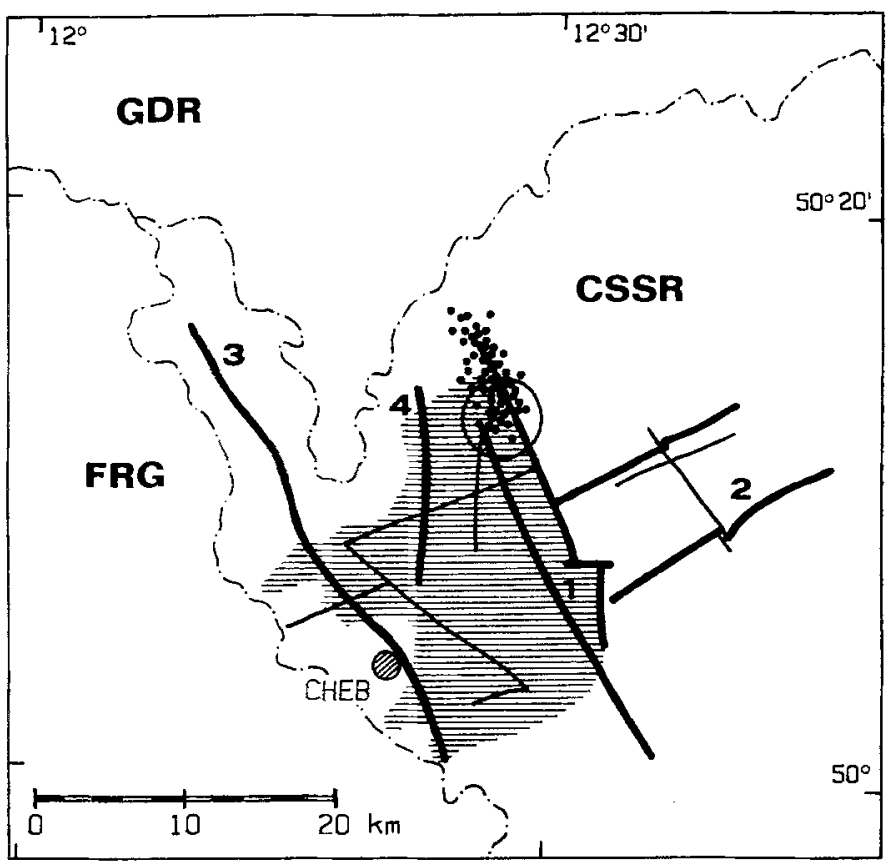

Figure I

Seismicity and geological data related to the 1985/86 West-Bohemian swarm. Epicentre of the main shock shown by an open circle (five different locations of the same shock, cf. Table 2), epicentres of weaker events of the swarm shown by dots. Four major fault zones shown by heavy lines 1-4, No. 1 represents the Mariánské Lázně fault. Other faults are denoted by thin lines and the Cheb sedimentary basin by the hatched area.

activity of these major faults suggest that they represent deep and significant lateral crustal heterogeneities. However, no detailed quantitative seismic-velocity models are available. The largest fault zones are crossed by many shorter and younger faults (see also Figure 1) and together they form a complex system of small blocks. Even the fault zones themselves are probably composed of many blocks. Relative movements of the blocks result in the swarm activity.

During the Tertiary, a sedimentary basin was formed in this area (Figure 1). The present surficial extent of "the Cheb basin" is about $25 \times 15 \mathrm{~km}$ and the thickness of the sediments reaches $300 \mathrm{~m}$. Its quantitative seismic model is not available, but geological drillings revealed a highly laterally varying depth of the crystalline basement. The region was volcanically active several times with the latest phase $8.10^{5}$ years ago. Mineral springs rich in $\mathrm{CO}_{2}$ are typical of the region. More details are given in ŠANTRŮČEK (1986), DUDEK (1987), MAHEL' et al. (1984) and several papers in ProcházKovÁ, ed. (1987).

Structural seismic model. Although the region under study has a complex 3-D seismic-velocity structure, the data available make it possible to propose only a horizontally layered (1-D) model. The model used in the present paper was derived 
by NovotNÝ (1983) and is given in Table 1. Absorption is considered in the simplest approximation of the frequency-independent and spatially invariable quality factor $Q$ of $S$ waves. Due to a lack of direct absorption measurements in the epicentral region, three values of $Q$ were tested $-Q=100,150$ and 200. They are considered together with the predominant frequency $f$ corresponding to macroseismic effects. The value of $\bar{f}=5 \mathrm{~Hz}$ was adopted in the calculations. Since the absorption effect is determined by the factor $\bar{f} \tau / Q$, where $\tau$ is the travel time, the results would be the same for $\bar{f}=10 \mathrm{~Hz}$ and $Q=200,300$ and 400 , respectively. All mentioned values of $Q$ seem reasonable for the area under study as indicated by WAHLSTRÖM and STRAUCH (1984). The results will be shown to be only weakly sensitive to the uncertain value of $Q$.

Instrumental earthquake data. Basic data on the main shock are given in Table 2. Five different epicentre determinations are listed there and shown in Figure 1. A part of weaker events of the swarm is also shown in Figure 1 (ZIMOVÁ and ŠPIČÁK, 1987). Their epicentre positions follow the M.L. fault, one of the major fault zones of the region. This fault strikes in about $\mathrm{N} 155^{\circ} \mathrm{S}$ azimuth.

Five fault-plane solutions of the main shock are listed in Table 2 and plotted in Figures 2a,b. All solutions are based on the first-motion $P$-wave polarities. Mechanism No. 1 in Figure 2a (ANTONINI, 1988) was derived from the largest data set consisting of 80 polarities. Only three stations (KOE, BMR and BDE) are not in agreement with this well constrained solution-strike $171^{\circ}$, dip $75^{\circ}$ and rake $-30^{\circ}$. It represents a left-lateral normal oblique faulting with a prevailing strike-slip character. Strike $171^{\circ}$ does not agree well with that of the M.L. fault which probably controls the swarm activity. Similar and even larger differences are found from focal mechanisms of several weaker events of the 1985/86 swarm (ANTONINI, 1988, ZAHRADNíK et al., 1989). These facts indicate a complex tectonic structure of the M.L. fault itself.

Fault plane solutions Nos. 2-5 (Figure 2b) are alternative interpretations of a smaller data set consisting of 35 polarities (ŠPIČ́Á, 1987). Solutions Nos. 2-4 are not satisfied by 5 polarities, solution No. 5 by 4 polarities. Though these solutions

Table 1

Crustal structure (according to NovOTNY, 1983)

\begin{tabular}{ccccc}
\hline $\begin{array}{c}\text { Layer } \\
\text { No. }\end{array}$ & $\begin{array}{c}\text { Thickness } \\
(\mathrm{km})\end{array}$ & $\begin{array}{c}P \text {-velocity } \\
(\mathrm{km} / \mathrm{s})\end{array}$ & $\begin{array}{c}S \text {-velocity } \\
(\mathrm{km} / \mathrm{s})\end{array}$ & $\begin{array}{c}\text { Density } \\
\left(\mathrm{kg} / \mathrm{m}^{3}\right)\end{array}$ \\
\hline 1 & 1 & 5.6 & 3.23 & 2820 \\
2 & 1 & 5.8 & 3.35 & 2860 \\
3 & 2 & 6.0 & 3.46 & 2900 \\
4 & 26 & 6.5 & 3.75 & 3000 \\
5 & 8 & $7.0-7.8$ & $4.04-4.50$ & $3100-3260$ \\
6 & $\infty$ & 7.9 & 4.56 & 3280 \\
& & & & \\
\hline
\end{tabular}


Table 2

Basic data on the main shock of the 1985/86 West-Bohemian swarm

Date: December 21, 1985

Origin time: $10 \mathrm{~h} 16 \mathrm{~m}$ (UT)

Epicentre coordinates ( 5 solutions):

\begin{tabular}{cccl} 
No. & Lat. N & Long. E & \multicolumn{1}{c}{ References and remarks } \\
\hline 1 & $50.21^{\circ}$ & $12.49^{\circ}$ & KLÍMA and RUPRECHTOVÁ $(1987)^{\mathrm{a}}$ \\
2 & $50.22^{\circ}$ & $12.50^{\circ}$ & KLÍMA and RUPRECHTOVÁ (1987) \\
3 & $50.23^{\circ}$ & $12.45^{\circ}$ & ZIMOVÁ and SPIĆÁ $(1987)^{\mathrm{a}}$, ANTONINI (1987) \\
4 & $50.22^{\circ}$ & $12.44^{\circ}$ & LOKAJíCEK et al. $(1987)$ \\
5 & $50.20^{\circ}$ & $12.45^{\circ}$ & PROCHÁZKOVÁ et al. $(1987 \mathrm{~b})$ p. 78 \\
\hline
\end{tabular}

Focal depth: $10 \mathrm{~km}$

Scalar moment: $\approx 10^{16} \mathrm{Nm}$

Plešinger and VAVRYČuK (1986)

Magnitude: 4.5

Focal mechanism ${ }^{\mathrm{b}}$ ( 5 solutions):

KÁRNÍK and ZEDNÍK (1987)

\begin{tabular}{|c|c|c|c|c|}
\hline No. & Strike & Dip & Rake & References \\
\hline 1 & $171^{\circ}$ & $75^{\circ}$ & $-30^{\circ}$ & ANTONINI (1988) \\
\hline 2 & $170^{\circ}$ & $70^{\circ}$ & $-40^{\circ}$ & ŠPICÁK (1987) \\
\hline 3 & $175^{\circ}$ & $80^{\circ}$ & $-35^{\circ}$ & ŚPICÁK (1987) \\
\hline 4 & $165^{\circ}$ & $60^{\circ}$ & $-40^{\circ}$ & ŚPIĊ́K (1987) \\
\hline 5 & $180^{\circ}$ & $85^{\circ}$ & $-60^{\circ}$ & SPIČ́Á (1987) \\
\hline
\end{tabular}

${ }^{a}$ Clusters of weak events of the swarm, supposed in the present paper to represent a possible location of the main shock.

${ }^{b}$ Angles defined after AKI and RICHARDS (1980).

are based on fewer data and different crustal models, two of them (Nos. 2 and 3) are very similar to No. 1. On the other hand, solution No. 4 gives the strike closer to the M.L. fault.

Macroseismic data. The main shock was macroseismically felt up to distances of about $300 \mathrm{~km}$ southeast and $150 \mathrm{~km}$ northwest. The entire macroseismic field was mapped by ProchÁzKoví et al. (1987a). As our intention is to analyze its asymmetry in connection with the source and tectonic elements of the epicentral region, we confine ourselves to the highest intensities, i.e., $I \geq 6^{\circ}$. For this special purpose the highest intensities were carefully reevaluated.

All intensity evaluations in this paper are based on the MSK-64 scale. Thus, no intensity values are assigned to individual reports or observations, e.g., from one building. Instead, the intensity corresponding to a certain site results from assessing relative frequencies of different damage types (1-3) in different types of buildings (A-C) over the whole site. In the case of the main shock, such an assessment was made by inspecting the majority of the sites ultimately classified by $I \geq 6^{\circ}$ in Czechoslovakia and $I>5^{\circ}$ in the GDR. During these inspections we received an insight into the connections between actual effects and their descriptions in macro- 


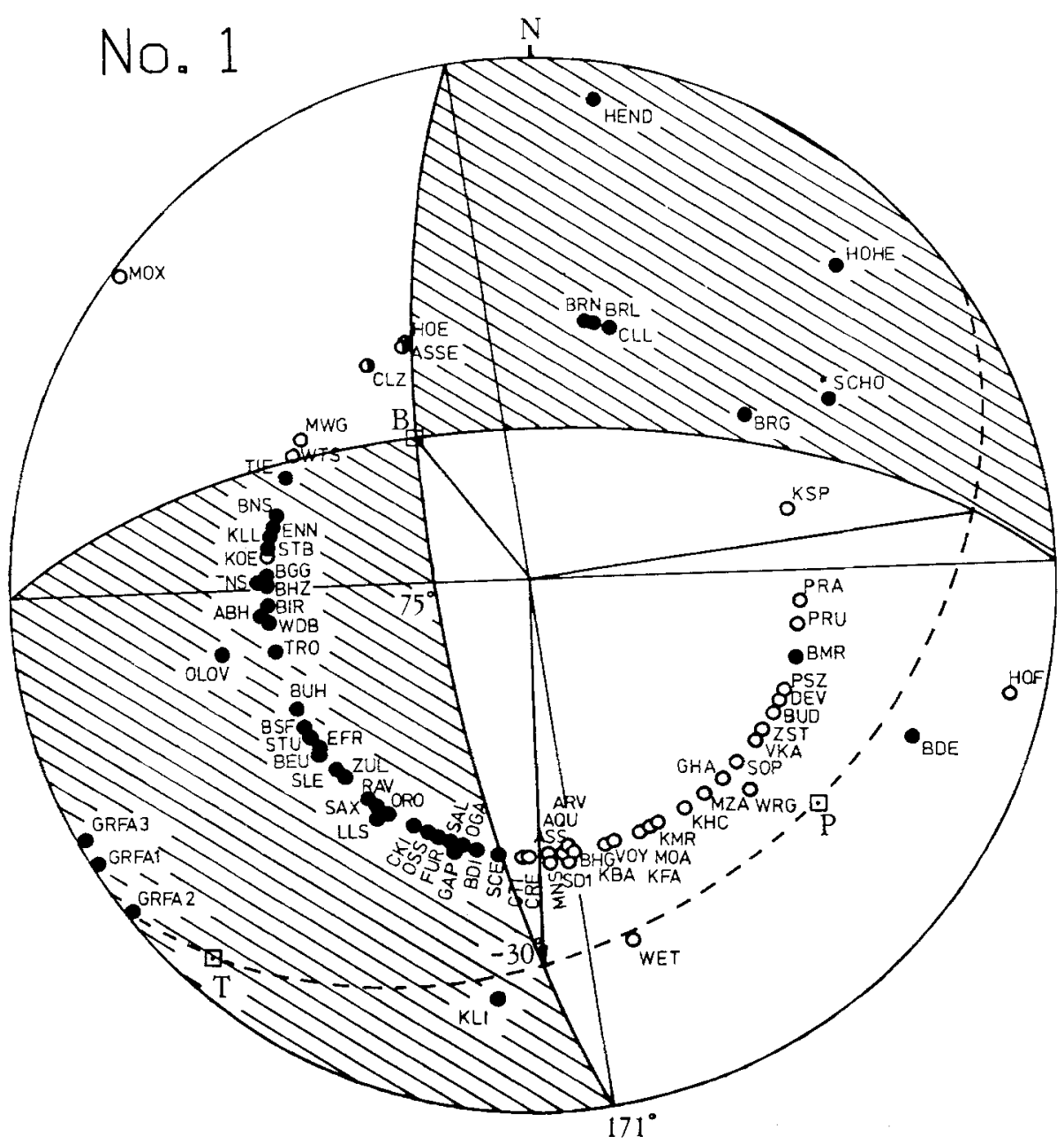

Figure 2a

Focal mechanism of the main shock, solution No. 1. Short period $P$-wave polarities are shown in the equal-area projection of the lower focal hemisphere. Solid circles - compressions, open circles - dilatations. For information on stations, see ISC (1987), DATA (1986) and ProcházkovÁ, ed. (1987). See also Table 2 .

seismic questionnaires. For several sites the intensities were assigned by means of standard questionnaires and written reports from local authorities, requested by us.

The most serious problems encountered during the intensity evaluation were the following:

i) Problems with the data compatibility from the three neighbouring countries under study.

ii) Problems of the absolute level of the intensity estimates.

In order to guarantee the compatibility, a joint inspection of selected sites in the 

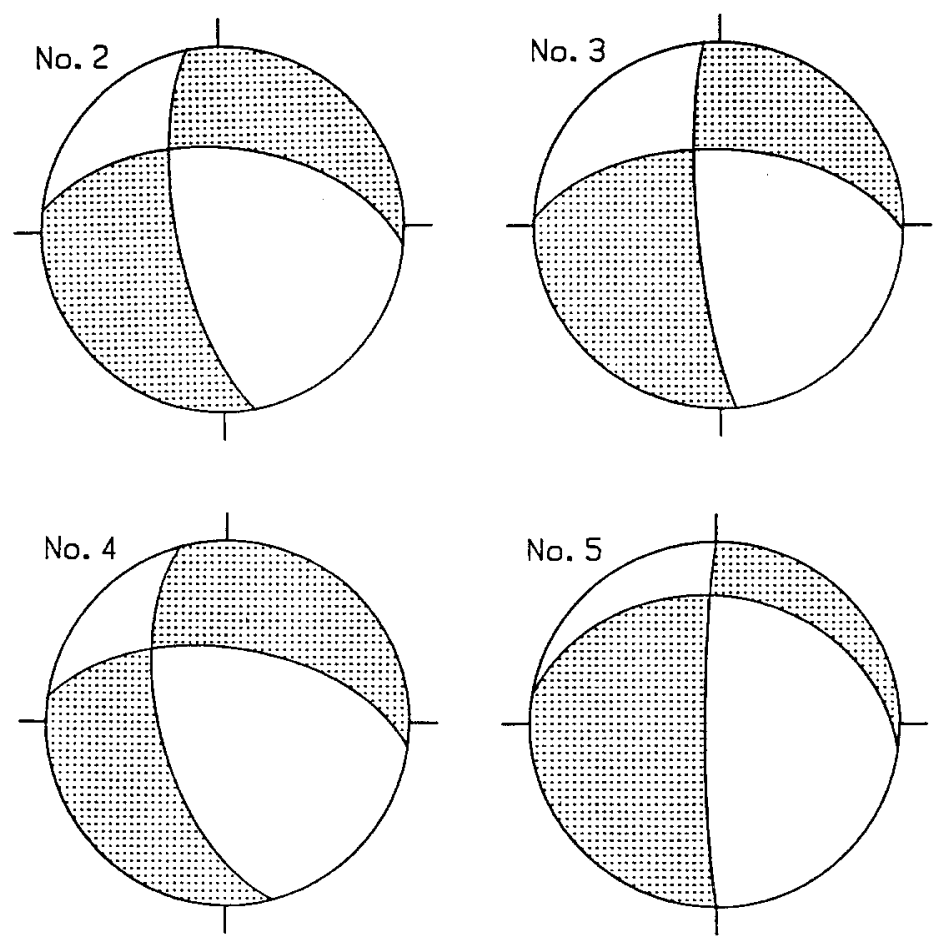

Figure 2b

Focal mechanisms of the main shock, solutions Nos. 2-5. See Table 2.

CSSR and GDR was performed, during which the participating authors agreed on a unified classification. The absolute-level problem was resolved by an independent study in the town of Cheb, the largest (27,000 inhabitants) in the studied region.

A detailed macroseismic survey was organised through seven schools in Cheb. About 4000 questionnaires were distributed and about 2500 usable replies were received. They covered 640 buildings, i.e., roughly one third of the town. Moreover, we visited several buildings recommended to us by local authorities as typical examples of the individual damage types. We realized during the statistical data processing that the MSK-64 scale offered no possibility of quantifying appropriately those sites with about 20 percent damage of type 1 or 5 percent damage of type 2 in buildings of type B. However, if we apply general classification principles used in the scale, it appears quite natural to add half a degree for the case like this $\left[6.5^{\circ}\right]$. For details see ZaHRADNík et al. (1987). Likewise, the $6.5^{\circ}$ "degree" should be characterized by 20 percent damage of type 2 and 5 percent damage of type 3 in structures of type A. For structures $C$, the $6.5^{\circ}$ value corresponds to 5 percent damage of type 1 . Based on our data on brick houses in Cheb, which we consider to be representative of buildings of type $B$, the adopted classification yields just the intensity $6.5^{\circ}$. 
All sites classified by $I \geq 6^{\circ}$ are plotted in Figure 3 and encircled by the $6^{\circ}$ isoseismal. This isoseismal has four lobes directed towards $\mathrm{E}, \mathrm{SE}, \mathrm{W}$ and $\mathrm{N}$. Their explanation represents the major objective of the present paper. Moreover, two sites deserve special attention-Skalná (S.) and Dolní Žandov (D.Z.). Skalná was assigned the largest intensity $-7^{\circ}$ although it is located as far as $8 \mathrm{~km}$ from the instrumental epicentre. Dolní Žandov represents the remotest $6.5^{\circ}$ site from the epicentre $(25 \mathrm{~km})$. These two "anomalous" sites are studied from the macroseismic point of view in greater detail in ZAHRADNík et al. (1987).

It is to be pointed out that no geological information was taken into consideration in determining intensities. In other words, the discussed intensities reflect the effects of the source, the crustal structure and geological site conditions. On the other hand, the influence of buildings is believed to be reduced through careful usage of the macroseismic scale.

Local conditions at the S. and D.Z. sites are little known. It was found that at the S. site, situated at the boundary of the Cheb basin, a layer of clay increases its thickness rapidly thus forming a pronounced wedge-shaped lateral heterogeneity. At

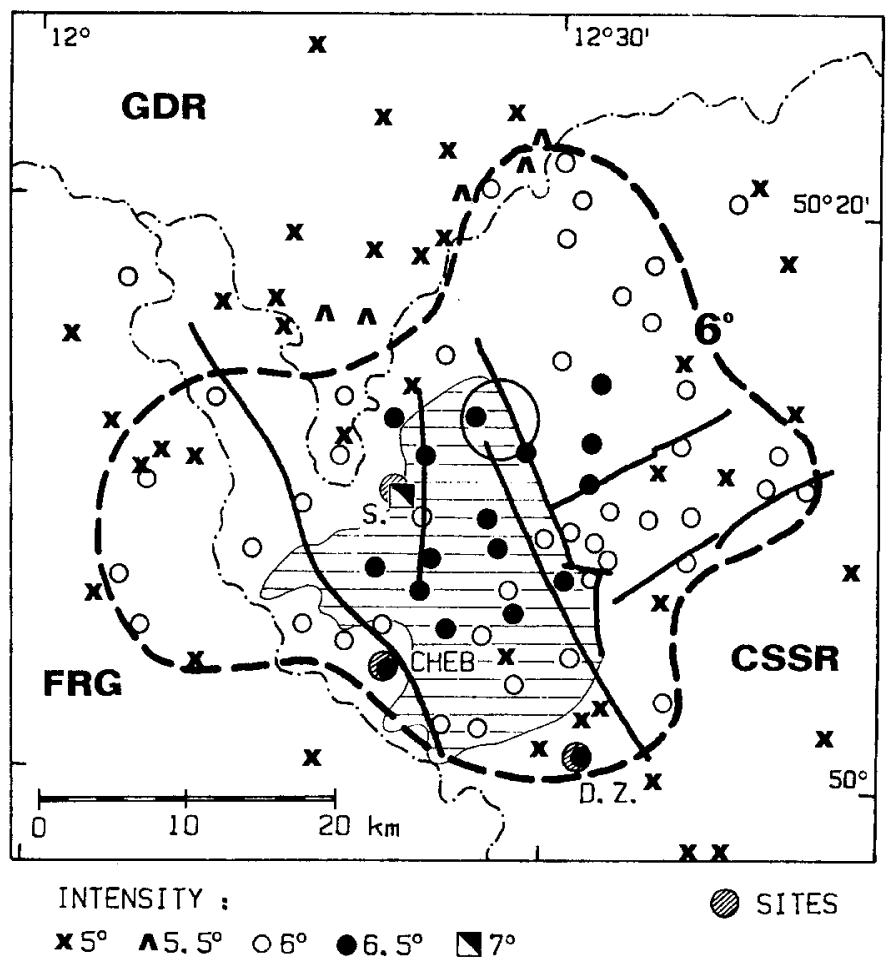

Figure 3

The observed macroseismic intensities of the main shock (with special emphasis to $I \geq 6^{\circ}$ ). The major faults and the Cheb sedimentary basin are also shown; cf. Figure 1. 
the D.Z. site the water level is very high ( $1-2 \mathrm{~m}$ below the surface) over a significant part of the village. Conditions like this could be responsible in principle for ground-motion amplifications (BARD and TUCKER, 1989; DRAVINSKI and MOSSESSIAN, 1987; MocZo et al., 1987; SÁNCHEZ-SESMA et al., 1988; ZAHRADNíK and Hron, 1987), but we have insufficient quantitative structural data to model them. Moreover, the scattered data available and our inspection revealed that not only these two sites but many others in the epicentral region might have been affected by pronounced local effects. Local effects are not of a primary interest in this paper, nevertheless, the analysis presented in Section 4 will partly touch on this question, too.

A qualitative interpretation of the macroseismic field (in terms of main structural elements). In Figure 3 major fault zones and the sedimentary basin are plotted together with the intensities. Some relations can be traced by comparing these important structural elements with the isoseismals. However, these relations are by no means simple and unambiguous. Thus, we cannot qualitatively explain the main features of the macroseismic field by the faults and the basin.

This conclusion is not surprising for several reasons. First, although the fault zones represent very pronounced geologic features, we do not know whether they also represent significant heterogeneities in seismic velocities and absorption. Second, the relation of the main shock to the major faults was probably not simple (e.g., see the preceding discussion about the M.L. fault strike and the focal-mechanism strikes). Third, the sedimentary basin is very likely to influence the ground motions. However, as shown e.g., by ZAHRADNíK and HRON (1987), the formation of local surface waves in sedimentary basins is sensitive to the overall bottom geometry; thus basins with complex asymmetrical cross-sections (as the Cheb basin probably is) may easily yield a ground-motion pattern that does not simply correlate with the surface boundaries of the basin.

For particular earthquakes and tectonic regions where special conditions occur (perhaps a pronounced source directivity and/or low-velocity fault zones etc.), faults and other geological elements can be correlated with macroseismic fields. In general, however, connections between geology and the macroseismic field might be very complex thus resulting in weak correlations. This means that some scepticism with respect to frequently reported "elongations of isoseismals along causative faults" is proper.

\section{Modelling the Macroseismic Field}

The preceding analysis has shown that connections between the macroseismic field and the main tectonic elements (Figure 3) are not very clear. As a suitable 3-D seismic model is available neither in a regional nor a local scale, we shall concentrate on effects of the seismic source upon the macroseismic field. 
Intensity and ground motion. It is not well understood to date which quantity characterizing the measured or computed ground motion is to be compared with intensity $I$. Peak ground-motion acceleration and velocity (PGA, PGV) and several integral measures, e.g., the root-mean-square acceleration (RMSA) were tested by several authors. For example, CHIARUTTINI and Siro (1981) found PGA-I relations with standard deviations comparable with the deviations in the currently used regressions between the PGA, the magnitude $M$, the source-to-site distance $D$ and the site geology. These PGA- $M-D$ relations have standard deviations of the order of 0.1-0.3 logarithmic units of PGA (BOORE and JoYNER, 1982). Surprisingly enough, the scatter in RMSA- $M-D$ relations was not found smaller (MCCANN and BOORE, 1983). On the other hand, MEDVEDEV (1978) reported a smaller scatter in $I$-PGV regressions as compared with the I-PGA ones. Our opinion is that macroseismic intensities reflect integral properties of the ground motion, i.e., not only peak values but also the duration and spectral content affect the intensity. We assume that the smallest scatter should be in relations between the intensity and integrated velocities. As far as we know the most extensive study of such relations was made by TRIFUNAC and BRADY (1975), hereafter referred to as T-B. One of their relations was of the form

$$
I=a+b \log _{10} \int_{0}^{\infty} v^{2}(t) d t,
$$

where $v(t)$ is the velocity-time history and the integration is performed over the whole significant duration of $v(t)$. The constants were found to be $a \doteq-1$ (for $v(t)$ measured in $\mathrm{cm} / \mathrm{s}$ ) and $b \doteq 0.5$ (independently of the units used for $v(t)$ ) for both vertical and horizontal components (Eq. 13 in T-B). Figure $2 \mathrm{~b}$ of T-B shows that for a given value of $\int v^{2} d t$ the uncertainty in $I$ is as high as \pm 2 for $I=3^{\circ}$ to $8^{\circ}$.

The uncertainty of constants $a$ and $b$ is due to several factors:

(i) In studying regressions like that in Eq. (1), one reocrd of $v(t)$ is usually used for a site (say a village) but the corresponding intensity $I$ is determined from many observations from that village. Thus local geological conditions within the site contribute to the scatter, not differences in local conditions from one village to another.

(ii) No scale completely eliminates the effect of building types and soil-structure interactions.

(iii) Each intensity determination is to some extent dependent on the seismologist's style in applying the macroseismic scale.

Because of factors like these it may even happen that intensity-velocity relations vary from one region to another. It is, of course, quite a different variability than that in PGA- $M-D$ relations that change from region to region due to physical reasons, e.g., different attenuation laws.

Generally speaking, the scatter of intensity-velocity relations should decrease by considering homogeneously determined intensities, regions with similar building 
types, small regions and narrow intensity bands. If we further confine ourselves only to intensity differences between individual studied sites (governed by constant $b$ only) the uncertainty decreases even more. For example, Figure $2 b$ of T-B shows that for $I$ from $5^{\circ}$ to $7^{\circ}$ the constant $b$ can be approximated very well by 1 . If $b=1$ and $b=0.5$ are taken as possible limits, the uncertainty of the intensity difference (for a given value of $\int v^{2} d t$ ) is about $0.5^{\circ}$ only.

Theoretical intensity. In the present paper we compute the ground motion and we need to scale it to make it comparable with the observed intensity. On the basis of the preceding discussion we assume (and a posteriori will verify) that a suitable definition of the theoretical intensity $I^{T H}$ is

$$
I^{T H}=a+\log _{10} \int_{0}^{\infty} v^{2}(t) d t .
$$

Here $b=1$ is used and the constant $a$ remains undetermined since we will confine ourselves only to the intensity difference between individual sites.

Our method of computing $I^{T H}$ was described in detail in ZAHRADNík (1989). Here only the most important assumptions and formulas are summarized. We consider the energy flux of shear waves generated by a circular double-couple source. In Eq. (2), $v$ stands for the ground-motion velocity corresponding to the three-component direct $S$ wave; $v=|v|$. To express $v$, the far-field representation is used after Eq. (14.9) of AKI and RICHARDS (1980). The radiation patterns $F^{s V}$ and $F^{S H}$ are taken from Eqs. (4.85) and (4.86) of the same book. The geometrical spreading $G$ is computed by the ray-method program based on ČERVENÝ and JANSKY (1985). The absorption correction is assumed to be $A=\exp (\pi \bar{\tau} \tau / Q)$ with $\bar{f}$, $\tau$ and $Q$ denoting the predominant frequency, the $S$-wave travel time and the $S$-wave quality factor, respectively. The surface correction is applied through $S$-wave conversion coefficients $q_{x}, q_{y}$ and $q_{z}$, corresponding to the radial, transverse and vertical components (p. 35 of ČERVENÝ et al., 1977).

If we assume that macroseismic effects correspond to $\bar{f}=5 \mathrm{~Hz}$ and the $S$-wave velocity at the source is $3.75 \mathrm{~km} / \mathrm{s}$, then the $S$-wave wavelength at the source $\lambda=750 \mathrm{~m}$ is comparable (or only slightly smaller) with respect to the characteristic source length of the event under study, $M_{0} \approx 10^{16} \mathrm{Nm}$. PLEŠINGER and VAVRYCuK (1986) estimated the effective source radius to be of $1-2 \mathrm{~km}$. This necessitates a finite source model. A single circular fault seems to be a sufficient approximation.

Energy-flux directivity of the circular source influencing the integral $\int_{0}^{\infty} v^{2}(t) d t$ of Eq. (2) is weak and simple. It is given by the function $e(\theta)$ and shown in Figure 14 of BoATWRIGHT (1980). Here $\theta$ denotes the angle between the ray leaving the source and the fault normal. The function $e(\theta)$ is almost constant with the exception of a narrow cone $\theta \in\left(0^{\circ}, 20^{\circ}\right)$ centered at the fault normal $\left(\theta=0^{\circ}\right)$ where $e(\theta)$ attains its maximum. This property makes the integral of velocity relatively easy to predict. This is the main idea of our approach, not very widely used until now for the intensity modelling. 
The only nonconstant (spatially variable) terms influencing the integral are:

$$
\varphi=\frac{|\mathbf{F}|^{2}}{G^{2} A^{2}} e(\theta), \quad \mathbf{F}=\left(F^{S V} q_{x}, F^{S H} q_{y}, F^{S V} q_{z}\right)
$$

Our method is based on computing the quantity $\varphi$ in a regular square grid of "observer" points at the earth's surface. The grid is centered at the epicentre with sides oriented NS (vertical) and WE (horizontal). The grid used in this paper covers the region $55 \times 55 \mathrm{~km}$. The computed values of $\varphi$ are normalized with respect to their maximum in the grid $-\varphi_{\max }$. Then we plot an areal distribution of

$$
\psi=\operatorname{INT}\left[10\left(\varphi / \varphi_{\max }\right)\right]
$$

and call it for simplicity a normalized energy-flux field. An example of the plot of $\psi$ is given in Figure 4. For discussion of Figure 4 see below. The values of $\psi$ between 10 and 1 are contoured and the contour is called the highest-valued synthetic isoseismal. The reason for this name stems from the fact that if we

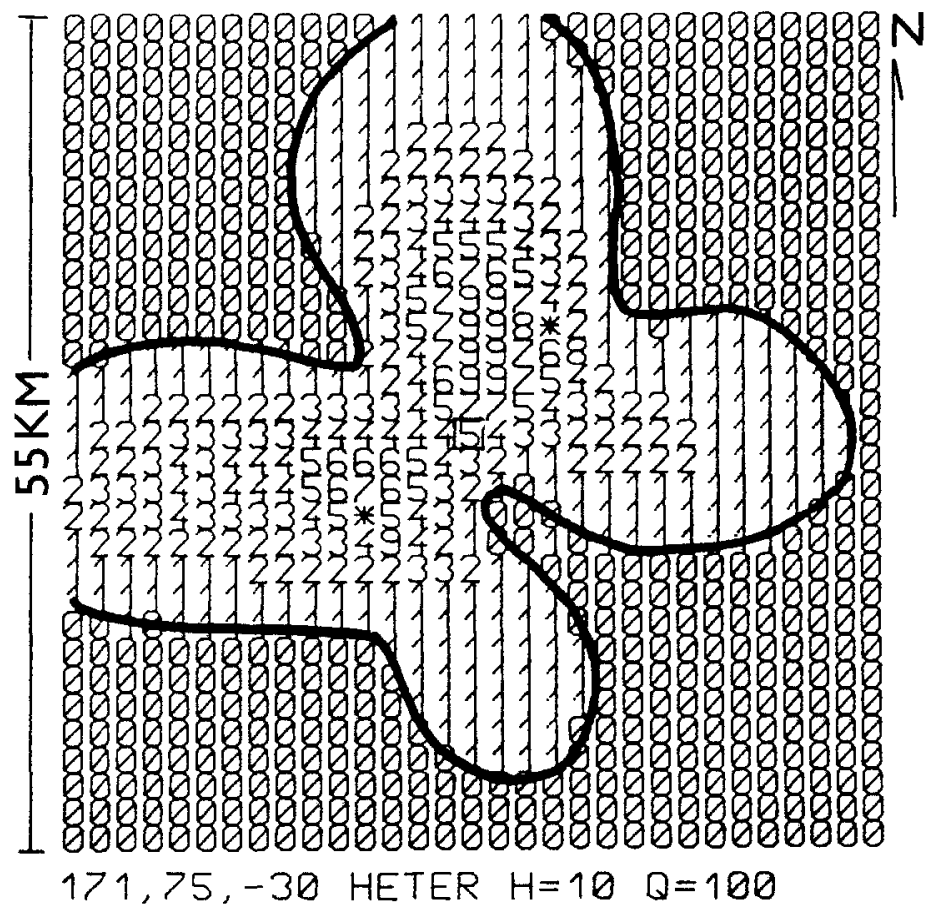

Figure 4

The normalized energy-flux field computed for the focal depth $h=10 \mathrm{~km}, Q=100$ and focal mechanism No. 1 (strike $171^{\circ}$, dip $75^{\circ}$ and rake $-30^{\circ}$ ). Instead of $\psi=10$ the star symbol is plotted. The epicentre is in the middle of the picture. The highest-valued synthetic isoseismal $6^{\circ}$ is denoted by a full line. 
substitute for velocity $v$ into Eq. (2) and denote all spatially invariable terms by $I_{m}^{T H}-1$, the theoretical intensity becomes

$$
I^{T H}=I_{m}^{T H}-1+\log _{10} \psi .
$$

As evident from Eq. (5) values of $\psi$ decreasing from 10 to 1 correspond to the intensity decrease of one degree, i.e., from $I_{m}^{T H}$ (the maximum theoretical intensity) to $I_{m}^{T H}-1$. Notice that our plots do not distinguish values $\psi<1$ which are formally displayed as $\psi=0$. In other words, the second and next isoseismals are not visualized in this paper.

Remark. The method described above does not require the source radius to be specified. It implicitly enters into the radiated seismic energy and together with other constants influences the absolute intensity values, not their normalized areal distribution studied here. Of equal advantage is the fact that we do not need to specify the direction of the rupture propagation (a radially rupturing fault is assumed). As a rule, the rupture-propagation direction is not known at routine level of seismological studies. The price we pay for such a simplicity is that our method obviously fails for earthquakes rupturing in a certain predominant direction, i.e., in situations that often arise with larger events.

Quantitative measure of the fit. To compare theory with observations, we use the intensity difference with respect to the maximum intensity $I_{m}^{T H}$ given by $I D^{T H}=I_{m}^{T H}-I^{T H}=1-\log _{10} \psi$. Correspondingly, the observed intensity, the maximum observed intensity and the observed intensity difference are denoted by $I^{O B}$, $I_{m}^{O B}$ and $D^{O B}=I_{m}^{O B}-I^{O B}$. Subscripts $i=1,2, \ldots, N$ denote the individual sites for which $I$ is available. For a description of an overall fit between theory and observations we then use the error

$$
E=\sqrt{\frac{1}{N-1} \sum_{i=1}^{N}\left(I D_{i}^{T H}-I D_{i}^{O B}\right)^{2}} .
$$

Due to reasons discussed in the preceding sections, each value $I D_{i}^{O B}$ can easily deviate from $I D_{i}^{T H}$ as much as $0.5^{\circ}$ even if the model used for computing $v(t)$ is quite exact (or if $v(t)$ is measured). However, any model differs from the reality which even increases the above-mentioned deviation. Locally for a given $i$ the deviation can very likely exceed $1^{\circ}$. For the epicentral region as a whole, the deviations partly cancel each other so that we shall consider the overall fit to be satisfactory for $E \leq 0.5^{\circ}$.

\section{Comparison Between Models and Reality}

First, the normalized energy-flux fields were generated for the crustal model of Table 1 with no absorption $(Q=\infty)$ assuming a trial value of the focal depth 
$h=7.5 \mathrm{~km}$. All five fault-plane solutions of Table 2 were subsequently used. These experiments were described in ZAHRADNíK (1989) and ZAHRADNíK et al. (1988). The best fit to the observed macroseismic field was found for mechanisms Nos. 1 and 3 of Table 2 for which the $6^{\circ}$ isoseismal was approximated well and the overall fit was characterized by $E=0.44^{\circ}$. The other mechanisms, the synthetic isoseismals of which gave visually a far worse fit, attained $E>0.5^{\circ}\left(0.52^{\circ}, 0.53^{\circ}\right.$ and $0.51^{\circ}$ for models Nos. 2, 4 and 5, respectively).

Second, we tried quite an idealized source model for a comparison, i.e., the isotropic point source formally described by $F^{S V}=F^{S H}=1, e(\theta)=1$. The structure, absorption and free-surface correction remained unchanged. This model also produced a minor error, $E=0.44^{\circ}$. Of course, its isoseismal is circular thus failing to explain any lobes. Moreover, the model contradicts the quadrantal distribution of the first-motion polarities. Nevertheless, the small error of the isotropic source is important to show that the overall "size" of the synthetic $6^{\circ}$ isoseismal is good. It gives a partial verification of the structural model, the focal depth and the constant $b=1$ in Eq. (2). It also shows that (at least for the studied earthquake) the focal mechanism cannot be easily constrained by macroseismic data. On the other hand, the small value of $E$ for the isotropic (evidently nonrealistic) source also indicates that this quantity is probably not ideal for quantifying the fit of synthetic and observed isoseismals in sufficient detail.

Third, we return to models with focal mechanisms Nos. 1 and 3. Their success, by using parameters $h=7.5 \mathrm{~km}$ and $Q=\infty$, indicates that more realistic absorbing models should probably have a larger focal depth. This indication was confirmed by ANTONINI (1987), who estimated $h=10 \mathrm{~km}$. Thus, the following experiments were carried out for $h=10 \mathrm{~km}$ together with finite values of $Q=100$, 150 and 200 tested for models Nos. 1 and 3. Since these two mechanisms give nearly identical results, we will no longer deal with model No. 3 . The case of No. 1 and $Q=100$ is presented in Figure 4. The results for $Q=150$ and 200 differ weakly with respect to that for $Q=100$, indicating only slight sensitivity to uncertainties in the absorption.

The energy-flux field of Figure 4 fits the macroseismic field with $E=0.43^{\circ}$. The maximum theoretical intensities (stars) and the synthetic $6^{\circ}$ isoseismal are compared with the observations in Figure 5. This figure represents the main result of the present paper. It shows that focal mechanism No. 1 based on the largest polarity set, the instrumentally determined hypocentre location and the horizontally layered crustal model explain well the main features of the macroseismic field. The overall fit $\left(E=0.43^{\circ}\right)$ is good and also the W, SE and E directed lobes are represented well by the model.

The most obvious misfit between the model and the reality is the $\mathrm{N}$ lobe. Although our model explains well the two areas of intensity $6^{\circ}$ on the GDR territory, and at least partially suggests why the two areas are separated by 


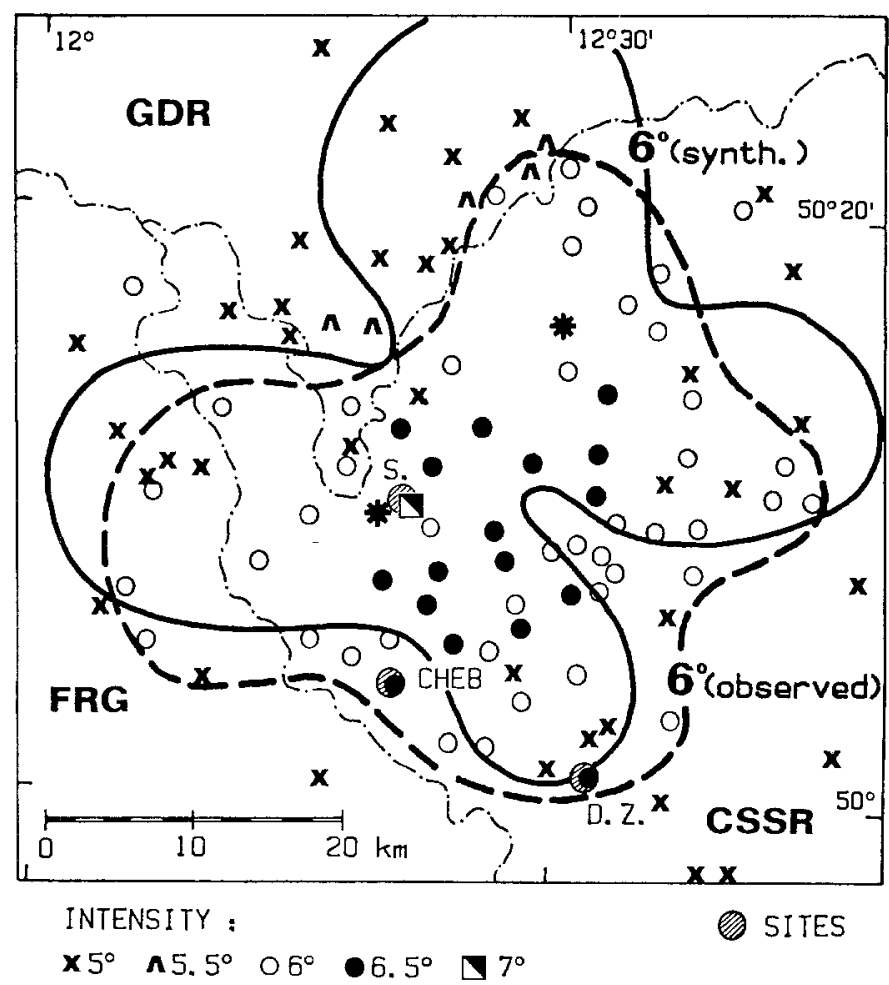

Figure 5

The comparison between the observed macroseismic field (Figure 3) and synthetic $6^{\circ}$ isoseismal of Figure 4. Theoretical maxima (stars) are also shown. The model agrees well with reality although neither lateral heterogeneities of the crust nor local conditions have been considered in the calculation.

intensities $5^{\circ}$ (see the NW minimum of the synthetic isoseismal in Figure 5), the model predicts deeper elongation of the macroseismic field into the GDR territory as compared to the observations. At present we have no quantitative seismic data to account for this discrepancy.

Surprisingly, Figure 5 also shows that one of the theoretical maxima nearly coincides with the maximum observed intensity at the Skalná site (S.). As explained in Section 2, local geological conditions such as those at S. may have affected the ground motion, too. Thus our result only indicates that the source effect should be considered a serious candidate for explaining the S. maximum, but not the only one.

As far as the other "anomaly" of the observations is concerned, the Dolni Z̆andov site (D.Z.), our model does not explain why $6.5^{\circ}$ was observed at such long distance from the epicentre. In that sense the model suggests the D.Z. anomaly to be probably due to local effects. 


\section{Conclusion}

In this paper, we have analyzed relations between the macroseismic intensities $I \geq 6^{\circ}$ of the magnitude 4.5 earthquake in West Bohemia, the crustal structure and the source. Local conditions at two sites were also considered. We have shown that the geological data indicate a complex 3-D laterally heterogeneous structure of the epicentral region. We have also shown that the macroseismic field has some geometrical relation (though not simple and convincing) to the major faults of the region and to the surface boundaries of the Cheb sedimentary basin. Because of the lack of quantitative seismic data for modelling the structural effects, we have studied the source effect by means of a simple horizontally layered crustal model.

The source model was assumed to be circular. Its double-couple focal mechanism and the hypocentre location were taken from independent instrumental studies. The intensity was assumed to be logarithmically proportional to the energy flux of a direct $S$ wave. The influence of the earth's surface and the absorption were taken into account approximately. Theoretical intensity distribution was compared with the observed one and the overall fit $E<0.5^{\circ}$ was found. In view of the simplifying model assumptions and uncertainties connected with the relations between the intensity and the ground motion, this fit can be considered acceptable. The model fits not only the overall "size" of the $6^{\circ}$ isoseismal, but also three of the four observed lobes. The present data can be equally well fitted by the isotropic source, too. This means that (for the earthquake under study) the focal mechanism cannot be easily constrained on the basis of the macroseismic data. Surprisingly, the model also gives its maximum theoretical intensity located close to the observed one regardless of the fact that no local geological conditions were introduced into the computation. These results serve as an important verification of the instrumentally determined source parameters and they also indicate a serious role of the source mechanism in forming the macroseismic field regardless of a significant structural complexity being suggested by geological data.

Last but not least the results encourage a wider application of the simple modelling technique used. Naturally, the method will probably approximate well only macroseismic fields of weak crustal earthquakes, particularly their highestvalued isoseismals, and a perfect fit will be found rarely. Nevertheless, we recommend this approach at least for two reasons: First, the method is extremely simple, applicable at a routine level of seismological studies when macroseismic fields and focal parameters need a joint interpretation. Second, discrepancies between macroseismic fields and their models will yield important guidelines for more sophisticated source-directivity studies and/or studies of lateral crustal heterogeneities and local effects.

Program MACRO for computing theoretical macroseismic fields is available on request from the first-named author. 


\section{Acknowledgements}

We thank Dr. H. Grosser who participated in preliminary focal-mechanism studies and Mrs. R. Zimová who drew all figures. Dr. P. Talwani and an anonymous reviewer provided constructive criticisms.

\section{REFERENCES}

AKI, K., and Richards, P. G., Quantitative Seismology (W. H. Freeman, San Francisco 1980).

ANTONINI, M., Statistics and source parameters of the swarm from digital recordings, In Earthquake Swarm 1985/86 in Western Bohemia (ed. Procházková, D.) (Geophys. Inst. Czechosl. Acad. Sci., Praha 1987) pp. 205-217.

ANTONINI, M., Variations in the focal mechanisms during the 1985/86 Western Bohemian earthquake sequence - correlation with spatial distribution of foci and suggested geometry of faulting, In Induced Seismicity and Associated Phenomena (ed. Procházková, D.) (Geophys. Inst. Czechosl. Acad. Sci., Praha 1988) pp. 250-270.

Bard, P. Y., and Tucker, B. E. (1989), Predictability of Sediment Site Amplification: A Case Study, Bull. Seismol. Soc. Am. (submitted).

BoATwright, J. (1980), A Spectral Theory for Circular Seismic Sources; Simple Estimates of Source Dimension, Dynamic Stress Drop, and Radiated Energy, Bull. Seismol. Soc. Am. 70, 1-27.

BOATWRight, J. (1986), Teleseismic Estimates of the Energy Radiated by Shallow Earthquakes, J. Geophys. Res. 91, 2095-2112.

Boore, D. M., and JoYner, W. B. (1982), The Empirical Prediction of Ground Motion, Bull. Seismol. Soc. Am. 72, 543-560.

Chiaruttini, C., and Siro, L. (1981), The Correlation of Peak Ground Horizontal Acceleration with Magnitude, Distance, and Seismic Intensity for Friuli and Ancona, Italy, and the Alpide Belt, Bull. Seismol. Soc. Am. 71, 1993-2009.

Červený, V., Molotkov, I., and PŠEnčtK, I., Ray Method in Seismology (Universita Karlova, Praha 1977).

ČervenÝ, V., and JANSKÝ, J. (1985), Fast Computation of Ray Synthetic Seismograms in Vertically Inhomogeneous Media, Studia geoph. et geod. 29, 49-67.

DATA Catalogue of Earthquakes in the FRG and Adjacent Areas 1982 (Bundesanstalt für Geowissenschaften und Rohstoffe, Hannover 1986).

Dravinski, M., and Mossessian, T. K. (1987), Scattering of Plane Harmonic P, SV, and Rayleigh Waves by Dipping Layers of Arbitrary Shape, Bull. Seismol. Soc. Am. 77, 212-235.

DUdEK, A. (1987), Geology and tectonic pattern of the Western Bohemian seismic area, In Earthquake Swarm 1985/86 in Western Bohemia (ed. Procházková, D.) (Geophys. Inst. Czechosl. Acad. Sci., Praha 1987) pp. 34-37.

Isc Regional Catalogue of Earthquakes for 1984 July-December, Vol. 21, No. 2 (Newbury 1987).

KÁRNíK, V., and ZEDNí, J., Amplitudes of $S g(L g)$ waves from the largest events of the swarm in West Bohemia and calibrating curves for near shocks, In Earthquake Swarm 1985/86 in Western Bohemia (ed. Procházková, D.) (Geophys. Inst. Czechosl. Acad. Sci., Praha 1987) pp. 255-260.

KLÍMA, K., and RUPRECHTOVÁ, L., The West-Bohemian earthquake swarm 1985/86-standard observatory data processing, In Earthquake Swarm 1985/86 in Western Bohemia (ed. Procházková, D.) (Geophys. Inst. Czechosl. Acad. Sci., Praha 1987) pp. 174-189.

LoKAJÍČEK, T., JANATKovÁ, Z., and PlomerovÁ, J., Travel times of seismic waves of the 1985-86 swarm in Western Bohemia, In Earthquake Swarm 1985/86 in Western Bohemia (ed. Procházková, D.) (Geophys. Inst. Czechosl. Acad. Sci., Praha. 1987) pp. 236-246.

MAHEL', M., KodYM, O., and MaLKovSKÝ, M. (1984), Tectonic Map of ČSSR, 1:500000, Geologický ústav Dionýsa Štúra, Bratislava. 
MCCANN, M. W., and BooRe, D. M. (1983), Variability in Ground Motions: Root-Mean-Square Acceleration and Peak Acceleration for the 1971 San Fernando, California, Earthquake, Bull. Seismol. Soc. Am. 73, 615-632.

Medvedev, S. V. (1978), Determination of the Seismic Intensity (in Russian), Voprosy inzhenyernoy seismologii $19,108-116$.

Moczo, P., BARD, P.-Y., and PŠEnČ́́k, I. (1987), Seismic Response of Two-dimensional Absorbing Structures by the Ray Method, J. Geophys. 62, 38-49.

NovotnÝ, O. (1983), Theoretical Dispersion Curves for the Seismic Profile Kašperské Hory (Czechoslovakia)-Ksiaz (Poland), Studia geoph. et geod. 27, 157-163.

PANZA, G. F., and Cuscito, M. (1982), Influence of Focal Mechanism on Shape of Isoseismals: Irpinia Earthquake of November 23, 1980, Pure Appl. Geophys. 120, 577-582.

PleŠINGer, A., and VAVRYČUK, V., Spectral and polarization analysis of broad-band digital recordings of the main shock of Dec. 21, 1985 (in Czech), In Počitačové spracovanie údajov československej seizmickej siete (eds. Mrázová, K., and Ruprechtová, L.) (Geophys. Inst. Slovak. Acad. Sci., Bratislava 1986) pp. 108-116.

ProcházkovÁ, D., ed., Earthquake Swarm 1985/86 in Western Bohemia (Geophys. Inst. Czechosl. Acad. Sci., Praha 1987).

ProcházKovÁ, D. (1988), 1985/86 Earthquake Swarm in Western Bohemia, Seism. Res. Letters 59, $71-78$.

ProcházkovÁ, D., Schmedes, E., and Drimmel, J., Isoseismal maps of the two strongest events during the earthquake swarm 1985/86 in Western Bohemia, In Earthquake Swarm 1985/86 in Western Bohemia (ed. Procházková, D.) (Geophys. Inst. Czechosl. Acad. Sci., Praha 1987a) pp. 104-109.

Prochazková, D., Tobyás, V., Soukup, J., Michek, R., and Knaislová, D., List of earthquakes in Westerm Bohemia, 1985-86, In Earthquake Swarm 1985/86 in Western Bohemia (ed. Procházková, D.) (Geophys. Inst. Czechosl. Acad. Sci., Praha 1987b) pp. suppl. 30-238.

Sánchez-Sesma, F. J., Chávez-García, F. J., and Bravo, M. A. (1988), Seismic Response of a Class of Allwwial Valleys for Incident SH Waves, Bull. Seismol. Soc. Am. 78, 83-95.

Suhadolc, P., Cernobori, L., Pazzi, G., and PanzA, G. F., Synthetic isoseismals: Applications to Italian earthquakes, In Seismic Hazard in Mediterranean Regions (eds. Bonnin, J., Cara, M., Cisternas, A., and Fantechi, R.) (Kluwer Academic Publishers, Dordrecht 1988) pp. 205-228.

SANTRŮČEK, P., Main structural features of the tertiary Cheb region (in Czech), In Počitačové spracovanie údajov československej seizmickej siete (eds. Mrázová, K., and Ruprechtová, L.) (Geophys. Inst. Slovak Acad. Sci., Bratislava 1986) pp. 22-30.

ŠpıČÁk, A., Fault plane solutions of 1985 Dec. 21 and 1986 Jan. 20 events, In Earthquake Swarm 1985/86 in Western Bohemia (ed. Procházková, D.) (Geophys. Inst. Czechosl. Acad. Sci., Praha 1987) pp. $268-273$.

Trifunac, M. D., and Brady, A. G. (1975), A Study on the Duration of Strong Earthquake Ground Motion, Bull. Seismol. Soc. Am. 65, 581-626.

Wahlström, R., and Strauch, W. (1984), A Regional Magnitude Scale for Central Europe Based on Crustal Wave Attenuation, Report No. 3-84, Seismological Department, University of Uppsala, Uppsala.

Zahradní, J. (1989), Simple Method for Combined Studies of Macroseismic Intensities and Focal Mechanisms, Pure Appl. Geophys. 130, 83-97.

Zahradní, J., Antonini, M., Grosser, H., Grünthal, G., Janský, J., Procházková, D., SCHMEDES, E., ŠPIČÁK, A., and ZEDNí, J., Joint interpretation of focal mechanisms and macroseismic data for the main event of West-Bohemian earthquake swarm 1985/86, In Induced Seismicity and Associated Phenomena (ed. Procházková, D.) (Geophys. Inst. Czechosl. Acad. Sci., Praha 1988) pp. $188-210$.

Zahradnik, J., and Hron, F. (1987), Seismic Ground Motion of Sedimentary Valleys - Example La Molina, Lima, Peru, J. Geophys. 62, 31-37.

ZAHRADNí, J., NovotNÝ, O., and CADEK, O., Intensity of the main shock of the West-Bohemian swarm 1985/86 in the town of Cheb and other sites close to epicentre, In Earthquake Swarm 1985/86 in Western Bohemia (ed. Procházková, D.) (Geophys. Inst. Czechosl. Acad. Sci, Praha 1987) pp. $64-67$. 
Zahradní, J., VAVRyčuk, V., JAnskÝ, J., and Zedník, J. (1989), Focal Mechanisms of Selected Events of the West-Bohemian Earthquake Swarm 1985/86 Constrained by P-wave Amplitudes, Revista de Geofisica, in press.

ZIMovÁ, R., and ŠPIČÁ, A., 1985/86 earthquake swarm in Western Bohemia-its possible relation to tectonic structure, In Earthquake Swarm 1985/86 in Western Bohemia (ed. Procházková, D.) (Geophys. Inst. Czechosl. Acad. Sci., Praha 1987) pp. 375-379.

(Received June 11, 1988, revised May 3, 1989, accepted May 31, 1989) 